\title{
Theory and Practice in Heron's Mechanics
}

\section{Citation}

Schiefsky, Mark J. 2007. Theory and practice in Heron's Mechanics. In Mechanics and Natural Philosophy before the Scientific Revolution, ed. W. R. Laird and S. Roux. Boston Studies in the Philosophy of Science 254. New York: Springer.

\section{Published Version}

doi:10.1007/978-1-4020-5967-4_1

\section{Permanent link}

http://nrs.harvard.edu/urn-3:HUL.InstRepos:3708561

\section{Terms of Use}

This article was downloaded from Harvard University's DASH repository, and is made available under the terms and conditions applicable to Other Posted Material, as set forth at http:// nrs.harvard.edu/urn-3:HUL.InstRepos:dash.current.terms-of-use\#LAA

\section{Share Your Story}

The Harvard community has made this article openly available.

Please share how this access benefits you. Submit a story.

Accessibility 


\title{
Theory and practice in Heron's Mechanics
}

\author{
Mark J. Schiefsky \\ July 2005
}

\section{Introduction}

In Greco-Roman antiquity, the art or science of mechanics ( $\mu \eta \chi \propto \nu ı$ ก غ̇тıбтท́ $\mu \eta$ ) encompassed a wide range of manual and intellectual activities, from the building of precision devices such as artillery and automata to the sophisticated theoretical analysis of machines in terms of concepts such as force and weight. As such, mechanics involved many different kinds of knowledge. Two key categories of mechanical knowledge may be distinguished: (1) theoretical knowledge, a set of relations between abstract concepts such as force and weight, sometimes couched in deductive form, and transmitted largely in written texts; and (2) practitioners' knowledge, arising in connection with the productive use of technology and acquired by practitioners in the course of their professional activity. A paradigm example of theoretical mechanical knowledge is the law of the lever, stated and proved by Archimedes as a precise quantitative relationship between forces and weights. But any practitioner who had made use of a lever would be familiar with the fact that it is easier to move a weight if it is placed closer to the fulcrum; a rough generalization of this kind, which can immediately be applied in practice, is a paradigm example of practitioners' knowledge. While it is crucial to distinguish between theoretical mechanics and practitioners' knowledge, there is substantial evidence of a two-way interaction between them in Antiquity. On the one hand, mechanical technology was sometimes developed by applying theoretical knowledge. But this was by no means always the case: new technologies often preceded any theory that could explain them. The growth of technology produced a set of problematic phenomena that called for explanation and thereby stimulated the growth of theoretical mechanics. ${ }^{1}$

The Mechanics of Heron of Alexandria, a work in three books which survives in its complete form only in an Arabic translation of the ninth century AD, is an especially fruitful source for studying the interaction between ancient theoretical mechanics and practitioners' knowledge. There is every reason to think that Heron was well informed about the technology of his time; his accounts of technological devices and procedures (mainly in books 1 and 3) have been confirmed by other literary accounts, archaeological evidence, and modern attempts to put them into practice. ${ }^{2}$ While the methods and devices that Heron describes are to some extent idealized, it would be rash to deny that his text can yield substantial information about the knowledge of ancient practitioners. As for theoretical mechanics, Heron mentions

\footnotetext{
${ }^{1}$ For a similarly wide conception of mechanics see the introduction to Pappus book 8, pp. 1022-30 Hu1tsch; at

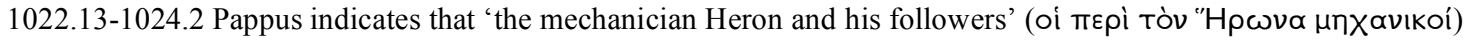

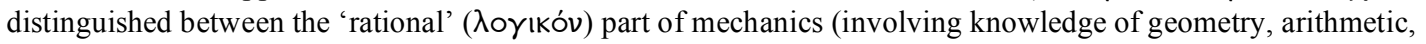
astronomy, and physics) and its 'manual' ( $\chi \notin ı \rho о u p \gamma ı$ ı́ $v)$ part (involving mastery of crafts such as bronze-working, building, carpentry, and painting). For the importance of distinguishing between theoretical knowledge and practitioners' knowledge see Damerow and Lefèvre (1994). On technology as applied theory see esp. Lewis (2001) on surveying instruments and other fine technology; Russo (2004), ch. 4 makes a powerful case that the impact of theory on technology in Antiquity has been greatly underestimated.

${ }^{2}$ Drachmann $(1963 \mathrm{~b}, 140)$ argues that the female screwcutter discussed in Mechanics 3.21 was a recent invention at the time when Heron wrote; see his account of a successful attempt to construct this device (Drachmann 1936). Cf. also Drachmann (1956), Drachmann (1932), and Drachmann (1963b), passim. Russo (2004, 130-7) argues that the technology described by Heron dates from the early Hellenistic period, i.e. several centuries before the time at which he lived (assuming this to be the first century AD). But even if this is right, it would not undermine the value of Heron's text as providing evidence of practitioners' knowledge (albeit of an earlier period).
} 
Archimedes by name some ten times in the Mechanics; he is cited as an authority for the proof of the law of the lever, which Heron makes no attempt to demonstrate himself. ${ }^{3}$ The second main source on which Heron drew for mechanical theory was the Aristotelian Mechanical Problems. Though it is not mentioned explicitly in the Mechanics, this work provides an important precedent for the core of Heron's theoretical project: the attempt to 'reduce' the five simple machines or mechanical powers (the wheel and axle, lever, compound pulley, wedge, and screw) to the circle and, ultimately, the balance (2.1-32). ${ }^{4}$

Heron's account of the five mechanical powers in 2.1-32 provides an excellent illustration of several aspects of the interaction between theoretical mechanics and practitioners' knowledge. First, it illustrates the way in which technology posed a challenge to theoretical mechanics. Each of the five powers made it possible to lift a large weight with a much smaller force; each therefore raised a challenge to the intuitive view, given support by Aristotle's natural philosophy, that a weight can only be moved by a force equal to it. Second, Heron's attempt to reduce the five powers to the balance brings out the importance of models in mediating between theoretical mechanics and practitioners' knowledge. The crucial step in Heron's reduction of each of the five powers is the identification of a similarity between the power in question and the balance; the intellectual operation is that of 'seeing' how each of the powers really is a kind of balance. In this way, the balance serves as a model that makes it possible to give an explanatory account of the five powers which traces their operation back to natural principles. Hence, despite the initially paradoxical or wondrous character of the effects they produce, the five powers (like other mechanical phenomena) can be integrated into the explanatory framework of natural philosophy: mechanics in Antiquity, no less than in the Renaissance, was part of the science of nature. Finally, Heron's account of the five powers, along with other closely related passages of the Mechanics, also reveals how the application of models could lead to conclusions that were sharply at variance not only with practitioners' knowledge but also with deeply held assumptions of much ancient natural philosophy, such as the notion that the motion of a body implies the presence of a force that moves it.

\section{The challenge of the five mechanical powers}

Before turning to Heron's account of the five powers, it is worth noting that the very notion of a mechanical 'power' or simple machine is attested for the first time in Heron himself. Of the five powers discussed in Mechanics 2.1-32, three-the wheel and axle, the lever, and the wedge - can be documented from very early times. ${ }^{5}$ All three are discussed in the Mechanical Problems, which probably dates from the early third century BC. ${ }^{6}$ The situation is somewhat different for the compound pulley and the screw. A passage in the Mechanical Problems may refer to the former, but the sense is disputed; various sources ascribe its invention to Archimedes. ${ }^{7}$ The screw is not mentioned in the Aristotelian text at all, and seems to have been an invention of the Hellenistic period; it may even have been

\footnotetext{
${ }^{3}$ Aside from a single reference to Posidonius in 1.24 (p. 62 Nix/Schmidt), no other figure is mentioned by name in the Mechanics. For Heron's references to lost works of Archimedes see Drachmann (1963a).

4 This and other parallels with the Mechanical Problems were noted and emphasized by Carra de Vaux in the introduction to his edition of Heron's Mechanics (1894, 22-4).

${ }^{5}$ Cf. Heron's remark (Mech. 2.2) that the lever was the first power to be developed, and that it was discovered by trial and error.

${ }^{6}$ The lever is discussed in problem $3(850 \mathrm{a} 30$ - b9), the wheel and axle in problem $13(852 \mathrm{~b} 11-21)$, and the wedge in problem $17(853 \mathrm{a} 20-31)$.

${ }^{7}$ Arist. Mech. 853a32 - b13 (prob. 18); cf. Drachmann (1956, 658), Krafft (1970, 44-6).
} 
developed as a specific application of a mathematical construction. ${ }^{8}$ However this may be, Heron is the first author we know of to identify this particular set of machines as making up a distinct group. The Hippocratic treatise On Fractures, which probably dates from the late fifth century $\mathrm{BC}$, mentions the winch, the lever, and the wedge as the three devices that enable human beings to achieve the greatest power. ${ }^{9}$ In the Mechanical Problems, while the lever is indeed treated as a simple machine to which other devices can be reduced, the pulley, wedge, and winch are not accorded any special status. ${ }^{10}$ Heron's recognition of the five powers as belonging to a special class is reflected in a terminological innovation, the use of the term

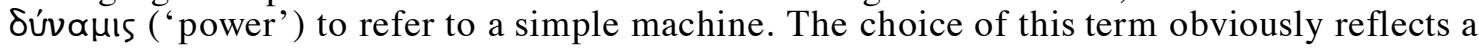
recognition that these machines could bring about especially powerful effects.

Thus the notion of simple machine seems to have developed in the period between the Mechanical Problems and Heron. Why? The reason surely lies, in part, in the great flourishing of technology during this period. The large-scale building projects of the Hellenistic age stimulated the development of new technology and provided extensive opportunities for its application. ${ }^{11}$ Moreover, many of the machines developed in this period involved the creative combination of the five powers. This is apparent from book 3 of the Mechanics, for example, where the combination of the wheel and axle, lever, screw, and pulley is characteristic of a number of cranes and presses. ${ }^{12} \mathrm{~A}$ further area of Hellenistic technology that demanded the combination of different machine elements was the building of automata: here the goal was to produce highly complex and varied motions from a single initial movement. ${ }^{13}$ The complex nature of ancient mechanical technology required practitioners to combine the wheel and axle, lever, pulley, wedge, and screw in creative ways; this ability went hand in hand with the identification of these devices as belonging to a special class, and was quite independent of any theoretical understanding of their operation.

Heron begins his account of the five powers with a description of their construction and use (2.1-6) that reveals a close familiarity with practitioners' knowledge. ${ }^{14}$ The construction of the wheel and axle (2.1), the compound pulley (2.4), and the screw (2.5-6) is described in detail. Two uses of the screw are described: with a wooden beam or tú $\lambda$ os (fig. 1), and with a toothed wheel (fig. 2). ${ }^{15}$ The account employs a good deal of specialized terminology for the

\footnotetext{
${ }^{8}$ Drachmann $(1963 b, 204)$.

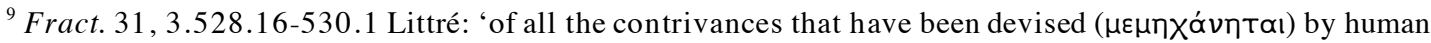

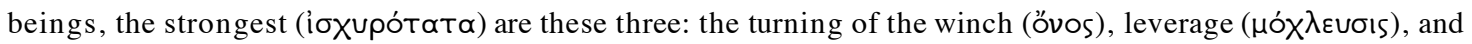
wedging ( $\left.\sigma \phi \eta^{\prime} \omega \omega \sigma \varsigma\right)$. Without these, either some one or all of them, human beings cannot accomplish anything that requires great strength'.

${ }^{10}$ Cf. Krafft $(1970,48)$.

${ }^{11}$ On the importance of large-scale urban planning in the Hellenistic period see Russo (2004, 203-9).

${ }^{12}$ See Drachmann (1956), Drachmann (1932), Drachmann (1963b, 94-140).

${ }^{13}$ See Heron's own treatise on the subject (the De automatis).

${ }^{14}$ Since the Greek text of these chapters was excerpted by Pappus (pp. 1114-1130 Hultsch), we can be reasonably certain about Heron's original terminology here.
}

${ }^{15}$ Note on figures: I agree wholeheartedly with Drachmann's emphasis (1963b, 20) on the need to take account of the original manuscript figures, which often deviate greatly from those of modern editions. I have therefore based my exegeses as far as possible on his drawings, which were made on the basis of personal inspection of both the British Museum (B) and Leiden (L) manuscripts. Nevertheless, the figures in the edition of Nix and Schmidt do not in my opinion seriously distort Heron's meaning in the sections of the Mechanics with which I am concerned here, and they may provide a helpful orientation for the modern reader unaccustomed to the rather limited drawing 
mechanical powers and their parts; a number of these technical terms are explicitly flagged as such using the Greek word $k \alpha \lambda \varepsilon \tilde{\sigma} \sigma \theta \alpha$, 'to be called '. ${ }^{16}$ A striking feature of Heron's account is the statement of rough, non-quantitative correlations describing the behavior of the five powers. Thus instead of a precise formulation of the law of the lever as a proportionality between forces and weights, Heron remarks that 'the nearer the fulcrum is to the load, the more easily the weight is moved, as will be explained in the following' (2.2). Similarly for the wedge, 'the smaller the angle of the wedge becomes, the more easily it exerts its effect' (2.4). In the case of the compound pulley Heron states that 'the more parts the rope is bent into, the easier it is to move the load' $(2.3) .{ }^{17}$ Generalizations such as these would have been familiar to any practitioner who had made use of the five powers, and do not presuppose a theoretical understanding of their operation. The explanation of such generalizations, as well as their restatement in exact quantitative terms, is one of the goals of the theoretical account that follows in 2.7-20.
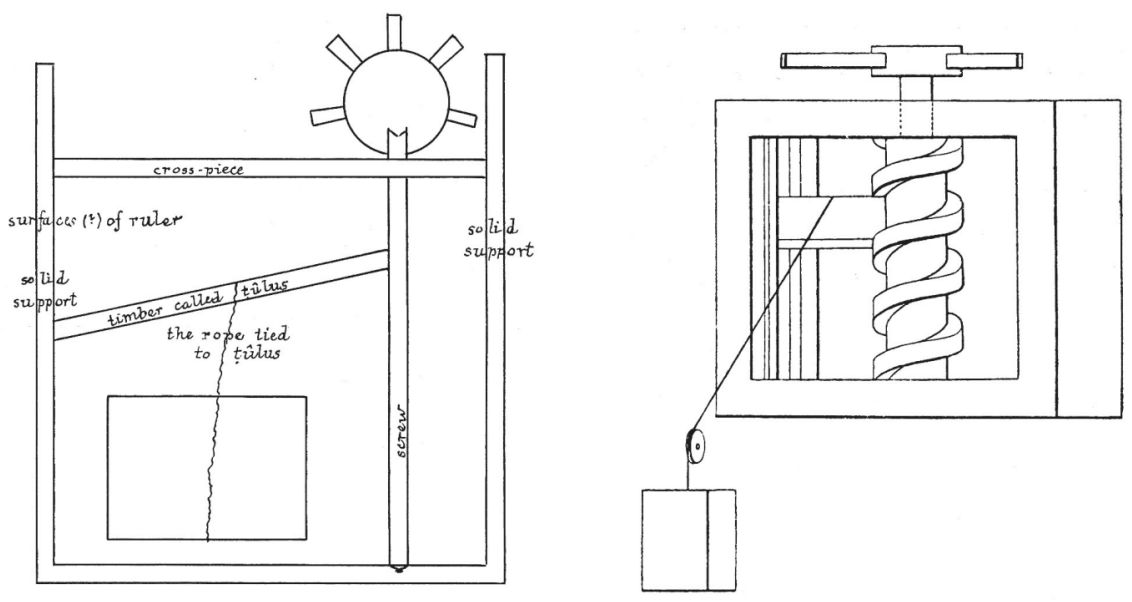

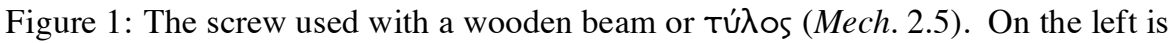
Drachmann's drawing made from MS B $(1963 \mathrm{~b}, 58)$; on the right is the figure from Nix/Schmidt.

techniques that are characteristic of the manuscripts. For these reasons, I include them alongside Drachmann's drawings in a number of cases.

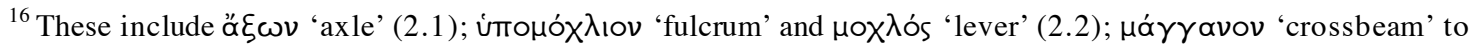

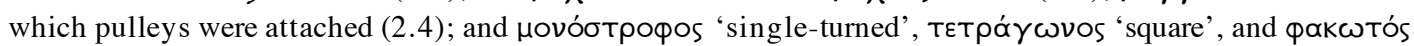
'lentilshaped' (2.5; each of these is a technical term for a type of screw).

${ }^{17}$ A close approximation to Heron's Greek text is given by Pappus, 1120.15-16 Hultsch; the Arabic translation of Heron garbles the meaning here (Drachmann 1963b, 55).
} 

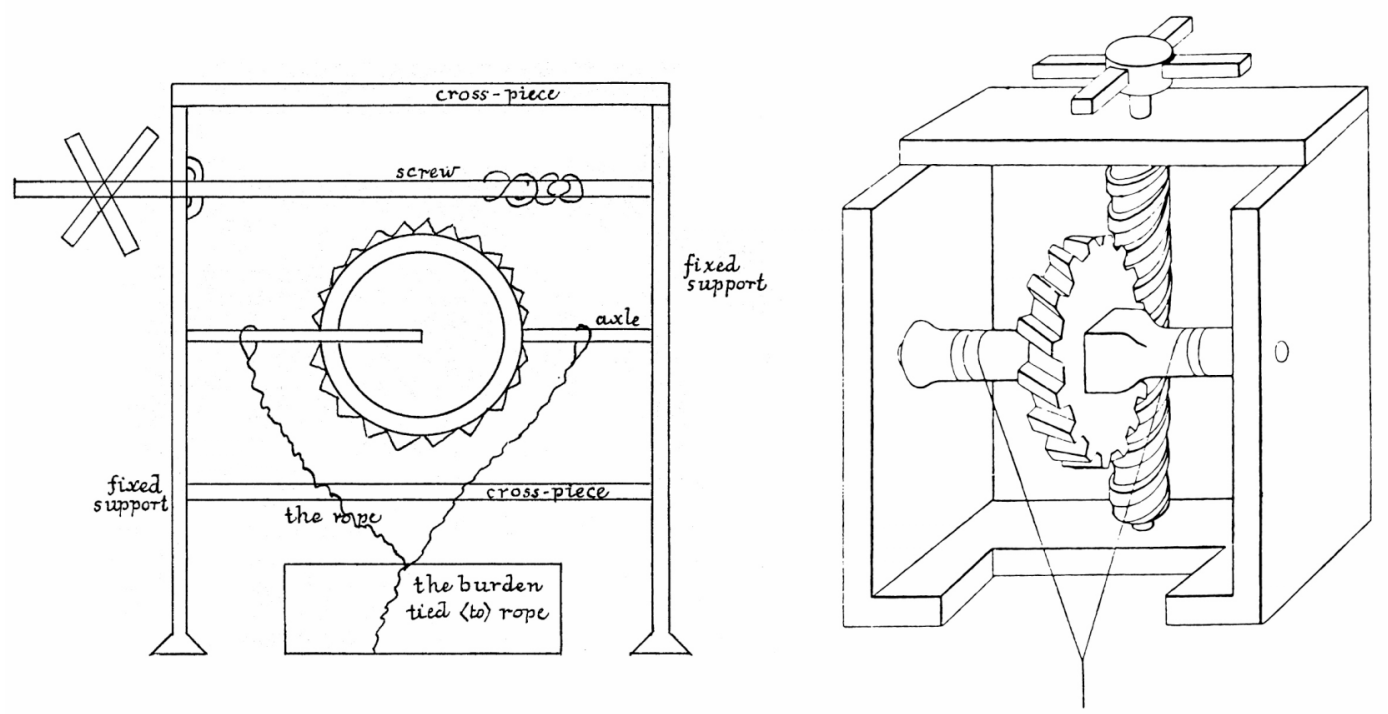

Figure 2: The screw used with a toothed wheel (Mech. 2.6). On the left is Drachmann's drawing from MS B (1963b, 61); on the right is the figure from Nix/Schmidt.

The key feature of each of the five powers that called out for theoretical explanation was their ability to move a large weight with a small force. In Heron's text this is expressed in a

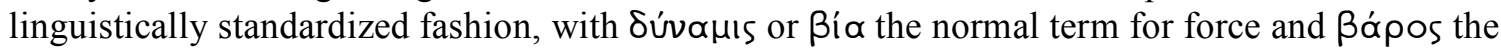
normal term for weight. ${ }^{18}$ The notion that a weight can only be lifted by a force that is equal to it was an assumption rooted in practical experience with devices such as the equal-armed balance or the simple pulley; Heron himself states in various passages of the Mechanics that to lift a weight without the use of a machine, a force equal to the weight is required. ${ }^{19}$ Moreover he consistently writes of forces as measured in units of weight, viz. the talent. In a passage from the Dioptra, a work extant in Greek, Heron explains what the assumption of a moving force of 5 talents amounts

\footnotetext{
${ }^{18}$ The somewhat complex terminological evidence may be summarized as follows: (1) Pappus, in the sections of his Mathematical Collection that contain excerpts from Mech. 2.1-7 (pp. 1114-1130 Hultsch), uses both ßía and

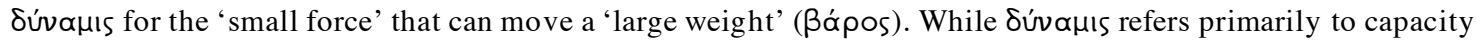
or ability and ßía to physical strength, it is evident that the capacity in question here is that of being able to lift a weight (cf. Heron, Dioptra 308.10-12 Schöne, quoted in the text above). Thus there is no important distinction of meaning between the two terms, and the Arabic translator quite reasonably renders both as quwwa (Jackson 1970). (2) A passage in Heron's Dioptra (ch. 37, pp. 306-12 Schöne) describes the Baroulkos or 'weight-hauler', a device that uses toothed wheels to move a 'given weight' by a 'given force' (below, fig. 10). In this description,

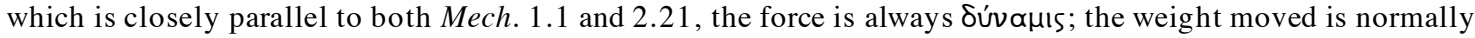
ßápos, but sometimes poptíov ('load'). (3) Pappus gives a slightly different description of the same device, which follows the same usage (pp. 1060-1068 Hultsch).

${ }^{19}$ Cf. Mech. 1.22 (p. 58 Nix/Schmidt): 'If we now want to lift the weight (tiql) to a higher place, we need a force (quwwa) equal to the weight (tiql)'; Mech. 2.3 (p. $98 \mathrm{Nix} / \mathrm{Schmidt):} \mathrm{'If} \mathrm{we} \mathrm{want} \mathrm{to} \mathrm{move} \mathrm{any} \mathrm{weight} \mathrm{(tiql)}$ whatever, we tie a rope to this weight (tiql) and we want to pull the rope until we lift it, and for this is needed a force (quwwa) equal to the weight (tiql) we want to lift', and especially Mech.2.34(i), p. 180 Nix/Schmidt: 'For there is no difference between the moving of a weight (tiql) and the moving of a force (quwwa) that is equal to that weight (tiql)'.
} 
to: '...that is, the moving man or slave should be one who can ( $\delta$ '́v $\alpha \theta \alpha$ l) move by himself without a machine 5 talents'. ${ }^{20}$ It was this intuitive relationship between force and weight, grounded in practical experience, that the five powers most dramatically called into question.

Seen from this perspective, Heron's account of the five mechanical powers stands in the same relationship to practitioners' knowledge as the Mechanical Problems. That text discusses a wide range of mechanical devices and phenomena drawn from the realm of

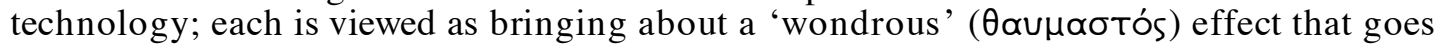

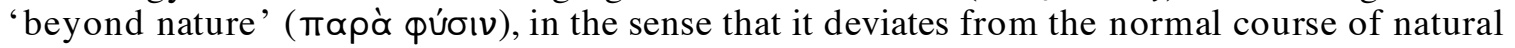
events and therefore demands a theoretical explanation. What makes such devices wondrous in particular is their ability to move a large weight with a small force; the paradigm example of such a device is the lever:

For it is strange that a great weight (ßópos) can be moved by a small force (ioxús), and that, too, when a greater weight ( $\beta$ ópos) is involved. For the very same weight ( $\beta \alpha$ ópos), which a man cannot move without a lever, he quickly moves by applying the weight ( $\beta$ ápos) of the lever. ${ }^{21}$

Though Heron's terminology is slightly different, the idea is the same. The five powers bring about effects that at first sight seem wondrous or paradoxical; the problem is to provide a theoretical explanation of how they do so.

\section{The reduction of the powers to the balance}

The core of Heron's account of the five powers is an attempt to reduce each power to a single principle, i.e. to explain by reference to a single principle why each power can move a large weight with a small force (2.7-20). The agenda for this section is set out in the opening sentence of book 2:

Since the powers by which a given weight (tiql) is moved by a given force (quwwa) are five, we necessarily have to explain their forms, their uses, and their names, because these powers are all reduced (mansüba) to the same nature ( $\left.\operatorname{tabi}^{\prime} a\right)$, though they are very different in form. ${ }^{22}$

In 2.7 Heron explains how a small force can balance a large weight in the case of weights placed on two concentric circles; he then goes on in the following chapters to argue that each of the five powers is analogous to two circles turning around the same center. Thus the explanation for each of the five powers is given indirectly, via the explanation for the concentric circles; in this way all the powers are 'reduced' or 'referred' (mansüba) to a single nature. This procedure has a close parallel in the Mechanical Problems, and was probably inspired by it. The introduction to the Mechanical Problems identifies the circle as the

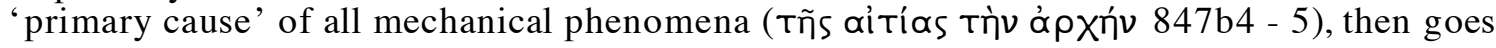

\footnotetext{
${ }^{20}$ Dioptra, p. 308.10-12 Schöne. The same explanation is given in Mech. 1.1: 'I mean that the man or youth who moves it is someone who can lift five talents by himself without any machine'.

${ }^{21}$ Arist. Mech. $847 \mathrm{~b} 2$ - 16. Translations from the Greek are my own unless otherwise indicated. Translations of Heron's Mechanics are based on Drachmann (1963b), which provides English versions made directly from the Arabic of most but not all the passages discussed in this paper. Translations of passages not in Drachmann are based on the German version of Nix (1900). In checking both Drachmann's and Nix's versions against the original Arabic, I have made extensive use of a set of tools for the computer-assisted analysis of Arabic texts developed in the context of the Archimedes Project at Harvard University (http://archimedes.fas.harvard.edu).

${ }^{22}$ Mech. 2.1. Translation Drachmann (1963b, 50), modified.
} 
on to make the following claim (848a12 - 15):

The things that occur with the balance are reduced (áváyєTal) to the circle, and those that occur with the lever to the balance, while practically everything else concerned with mechanical motions is reduced to the lever.

In the remainder of the text the author closely follows the program suggested by this remark. He first explains how the behavior of the balance can be explained by reference to the circle (problems 1-2), then shows that the lever can be explained by reference to the balance (problem 3); the rest of the treatise discusses a wide range of mechanical phenomena and instruments, most of which are explained by reference to the lever. The key explanatory strategy is the identification of similarities between mechanical phenomena and the circle, whether directly or indirectly via analogies with the balance and/or lever. In this way the circle, balance, and lever function as simple models that enable an explanation to be given of all mechanical phenomena. The parallel with Heron extends also to the level of terminology: the term a'vóyeTal, used by the author of the Mechanical Problems in the sense of 'reduce' or 'refer', probably corresponds to mansūba in the passage from Mechanics 2.1 quoted above. ${ }^{23}$ Thus when Heron remarks in reference to the concentric circles that 'the ancient authors, who came before us, have also started from this starting point' (2.8), he probably has the Mechanical Problems itself in mind. ${ }^{24}$

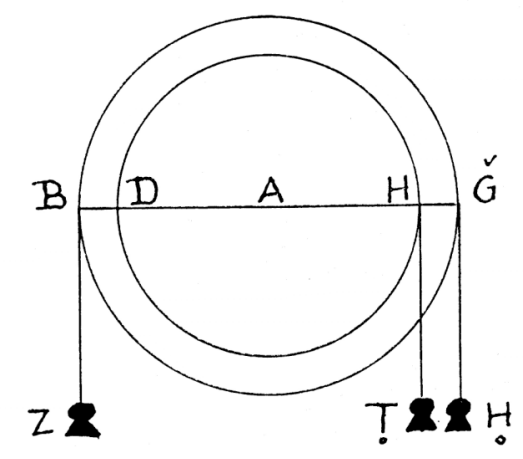

Figure 3: Equilibrium on concentric circles (Mech. 2.7). Drachmann's drawing (1963b, $62)$ is from the Leiden MS (L).

Heron's account of the concentric circles is given in 2.7 (cf. fig. 3). We are to imagine two circles free to rotate about the same center. If two equal weights $Z$ and $H$ are suspended at points $B$ and $\breve{G}$, it is clear that the line BČ will remain parallel to the horizon, '....because the two weights $Z, H$ are equal and the two distances $B A, A C ̌$ are equal, and BČ is a balance beam turning on a point of suspension, which is the point $A \cdot \cdot{ }^{25}$ Now if weight $\dot{H}$ is shifted inwards

\footnotetext{
${ }^{23}$ This seems clear from a comparison with the parallel version in Pappus (p. 1116 Hultsch), which states that

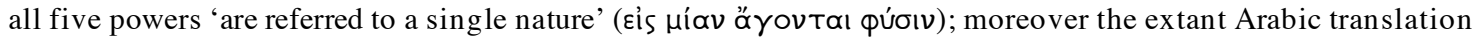

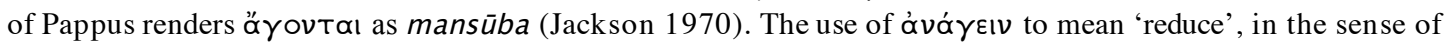
bringing a diversity of cases under a small number of general principles, is Aristotelian; see GC 330a25, $P h$. 189b27, Metaph.983a28, A Pr. 29 b1.

${ }^{24}$ Translation Drachmann (1963b, 63).

${ }^{25}$ Translation Drachmann (1963b, 62).
} 
and suspended from the diameter of the smaller circle at $\mathrm{H}$ so that it comes to be at T, the circles will turn in the direction of weight $Z$. But if the weight at $T$ is then increased so that its ratio to the weight $Z$ is as the ratio of $B A$ to $A H$, the imaginary balance beam (now $B H$ ) will again be in equilibrium and take up a position parallel to the horizon. To support this claim Heron appeals to Archimedes' proof of the law of the lever in On the Equilibrium of Planes. ${ }^{26}$ Finally he draws the following conclusion:

From this it is evident that it is possible to move a great bulk by a small force (quwwa). For when the two circles are on the same center and the great weight (tiql) is on an arc from the small circle and the small force (quwwa) is on an arc from the great circle, and the ratio of the line from the center of the big one to the line from the center of the small one is greater than the ratio of the great weight ( $\underline{t} i q l)$ to the small force (quwwa) that moves it, then the small force (quwwa) will overpower (qawiya) the great weight $(\underline{t} i q){ }^{27}$

Several points about this procedure call for comment. First it is clear that Heron makes no attempt to prove the law of the lever; rather, he accepts it as a result already demonstrated by Archimedes. Second, the analogy with the balance plays a crucial role: both BČ and BH are explicitly identified with the beam of a balance suspended from point $A$. In fact, what Heron describes is a kind of compensation procedure that would have been familiar to any practitioner who had worked with a balance with unequal arms. In such balances, the effect on equilibrium of moving a weight closer to the suspension point can be compensated by increasing the weight at that point. This suggests a general equivalence between the addition of a weight to the balance and the displacement of a weight along the beam. ${ }^{28}$ Third, Heron describes equilibrium as a relationship between force and weight: a small force (Arabic quwwa) balances a large weight (Arabic tiql). This terminology recurs throughout Heron's account of the five powers, which are consistently described as able to move a large weight (tiql) by means of a small force (quwwa). Equilibrium is understood as an equivalence between a small force and a large weight, rather than between composite quantities (e.g. the product of weight and distance from the suspension point) ${ }^{29}$ Thus Heron remarks that in the Baroulkos or 'weight-hauler', a device that uses toothed wheels to lift a weight of 1000 talents with a

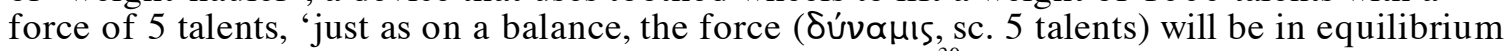

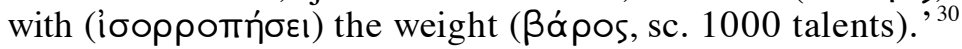

\footnotetext{
${ }^{26}$ At 2.7, p. 114.5-7 Nix/Schmidt Heron states that 'Archimedes has proven this in his book on the equalizing of

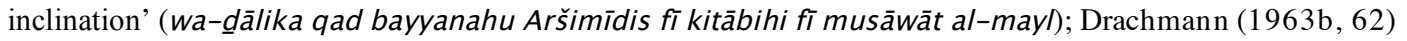
plausibly takes the reference to be to On the Equilibrium of Planes.

${ }^{27}$ Translation Drachmann $(1963 b, 62)$, slightly modified.

${ }^{28} \mathrm{Cf}$. the treatise On the Balance attributed to Euclid, which is extant only in an Arabic version (Clagett 1979, 24-28). This text first demonstrates the equivalence of (a) adding a certain amount to a weight on a balance and (b) displacing that weight a certain distance along the beam; it then goes on to use this equivalence to prove the law of the lever.

${ }^{29}$ Compare the Euclidean text mentioned in the previous note, which coins a new term, 'force of weight' (quwwat altiql) to express the effect of (a) adding a weight to the balance at a certain distance from the suspension point, or (b) displacing a weight by a certain amount along the beam. Thus a weight suspended at a certain distance from the suspension point can be said to be equivalent to a certain segment of the beam in 'force of weight' (Clagett 1979, 27-9).

${ }^{30}$ Dioptra, 310.26-7 Schöne; cf. below, p. XREF. Pappus makes the same point in the same language (p. 1066 Hultsch).
} 


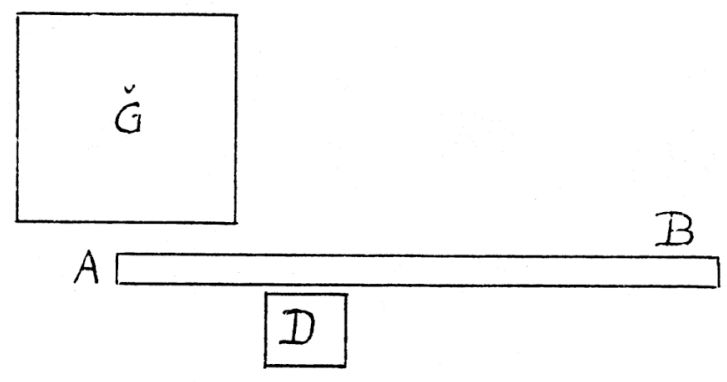

Figure 4: The lever, first use (Mech. 2.8). Drachmann's drawing is from the Leiden MS (1963b, 63).

In the case of two of the five powers, the reduction to the circle is immediate. When the lever is used to lift a weight completely off the ground, as illustrated in fig. 4 (2.8), the moving force (al-quwwat al-muharrikat) applied at its end (B) is identified with the force applied to the circumference of the larger circle, the weight (tiql) to be lifted (Ǧ) with the weight on the arm of the smaller circle, and the fulcrum (D) with the center of the two circles. Since the ends of the lever trace out arcs on concentric circles as the weight is lifted, the analysis of 2.7 can be applied directly: if the ratio of the length of the longer arm BD to that of the shorter arm DA is equal to the ratio of the weight $\breve{C}$ to the moving force applied at $B$, the lever is in equilibrium; if it is greater than the ratio of Č to B, the force will lift the weight. ${ }^{31}$ The reduction of the wheel and axle to the concentric circles is just as direct $(2.10$; fig. 5). The wheel corresponds to the larger circle and the axle to the smaller; the weight (tiql) is hung from the axle and the moving force (al-quwwat al-muharrikat) applied at the circumference of the wheel. ${ }^{32}$
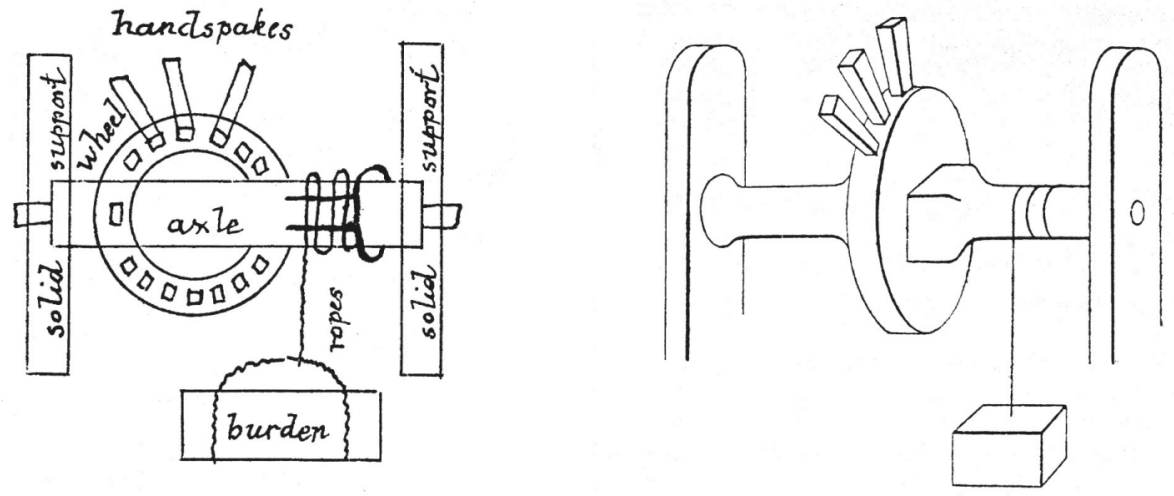

Figure 5: The wheel and axle (Mech. 2.1, 2.10). On the left is Drachmann's drawing made from the Leiden MS (1963b, 51); on the right is the figure from Nix/Schmidt.

\footnotetext{
${ }^{31}$ On the second use of the lever, discussed in Mech. 2.9, see below, p. XREF.

${ }^{32}$ Heron himself remarks in 2.10 that he has included a the wheel and axle only for the sake of completeness: 'And this is what those before us have already told; we have explained it here, however, just to make our book complete and to give it an orderly composition'. Translation Drachmann (1963b, 67); cf. Arist. Mech. 852b11 - 21.
} 


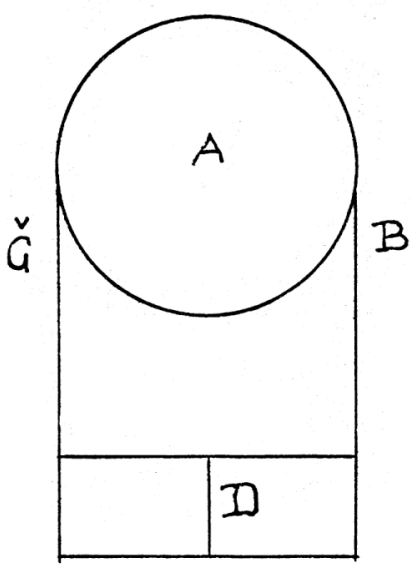

Figure 6: The simple pulley (Mech. 2.11). Reconstruction by Drachmann $(1963 \mathrm{~b}, 69)$ on the basis of drawings in the Leiden MS.

The analysis of the compound pulley, though more complex, nonetheless begins from a direct application of the reasoning of 2.7. The first step is to imagine a weight suspended from two ends of a rope wound around a simple pulley (2.11; fig. 6). Both segments stretching from the pulley to the weight will be equally taut, and each will carry half the weight. If the weight is divided into two equal parts, each one will balance the other, just like the two weights suspended on the circumference of the larger circles in 2.7. This result is then generalized to cover multiple pulleys and ropes, and the result is precise quantitative relationship:

...the ratio of the known weight ( $\underline{t i q l)}$ to the force (quwwa) that moves it it is as the ratio of the taut ropes that carry the weight to the ropes that the moving force (al-quwwat almuharrikat) moves. ${ }^{33}$

For example, in fig. 7, each of the four lengths of rope stretched between the weight $Z$ and the two pulleys on $A$ carries $1 / 4$ the total weight. If we imagine detaching the rightmost section of the weight $Z$ from the sections ČBT, it will hold those sections in equilibrium. Thus a force equal to $1 / 4$ the total weight of $Z$, applied at $K$, balances $3 / 4$ the total weight (ČBT ), and a slightly larger force will move it. ${ }^{34}$

\footnotetext{
${ }^{33}$ Mech. 2.12. Translation Drachmann (1963b, 70), modified.

${ }^{34}$ In general, letting $F$ represent the moving force, $W$ the weight, and $n$ the total number of segments of rope that bear the weight, we have $F: W:: 1: n$.
} 

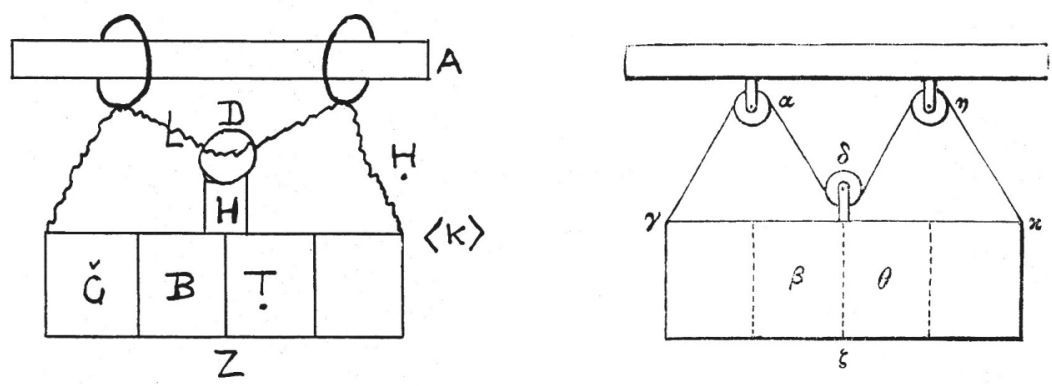

Figure 7: The compound pulley (Mech. 2.12). Drachmann's drawing from MS L is on the left $(1963 \mathrm{~b}, 70)$, the figure from Nix/Schmidt is on the right.

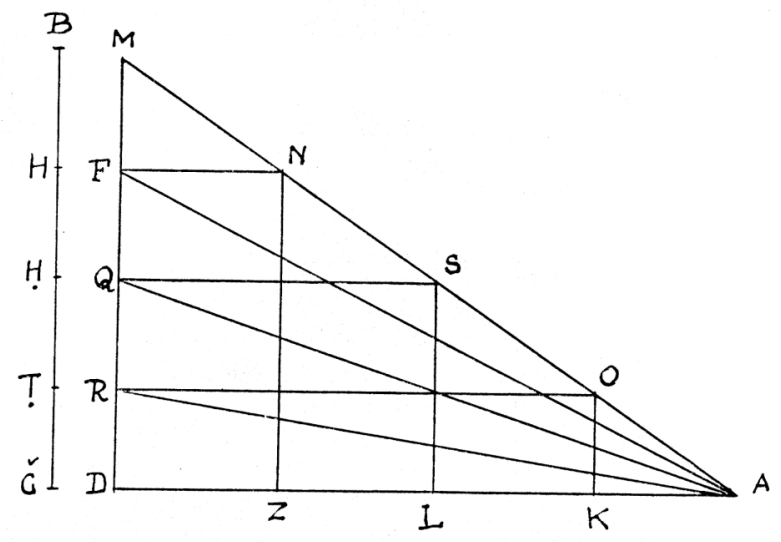

Figure 8: The wedge (Mech. 2.15). Drachmann's drawing is from MS L (1963b, 72).

In the case of the wedge and screw the similarity to the concentric circles is much less clear. Since Heron claims that the screw is simply a twisted wedge (2.17), I shall concentrate here on the analysis of the wedge in 2.15 (cf. fig. 8). ${ }^{35}$ The argument is in two stages. (1) First Heron claims that 'any blow, even if it is slight, will move any wedge'. The idea is to divide the contribution of a single blow (represented by BČ) to the movement of the wedge into the contributions of a number of arbitrarily small sub-blows $(\mathrm{BH}, \mathrm{HH}, \mathrm{HT}, \mathrm{T}, \mathrm{G})$. The total movement produced by the entire blow is simply the sum of the movements produced by each of the sub-blows. Hence any blow, however small, will move the wedge a certain distance. (2) Second, Heron imagines dividing the wedge into as many sub-wedges (MF, FQ, $\mathrm{QR}, \mathrm{RD})$ as the sub-blows (BH, HH, HTT, ȚČ). He argues that each sub-wedge, struck by a sub-blow, covers the same lateral distance $A D$ in the same time as the whole wedge, struck by the whole blow BČ. The argument is as follows. If the whole wedge is struck by the whole blow

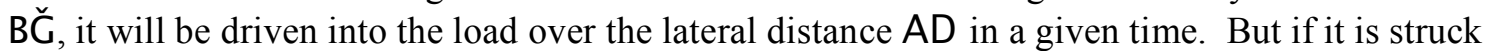
by a smaller force, the sub-blow $\mathrm{BH}$, it will be driven into the load over the distance $\mathrm{AK}$, where $A K$ : AD :: BH : BČ. Now if this same sub-blow is exerted on the sub-wedge RD, it will be driven in over the entire distance $A D$. The reason is that the displacement of the load (i.e. KO, the distance it is moved along the vertical axis) is the same whether the whole wedge is driven in over the distance AK or the sub-wedge over the distance AD: the same force (BH), acting for

\footnotetext{
${ }^{35}$ Note however that the analysis of the screw as a twisted wedge is supported by explicit reference to a practical procedure for making a screw, viz. by winding a right-angled triangle around a cylinder (2.16-17).
} 
the same time, produces the same displacement of the load (KO) in both cases. ${ }^{36}$ The upshot is that the sub-wedge RD will be able to split the load just as much as the whole wedge MD by means of a smaller force; this force, however, will have to act for a proportionally longer time:

And if that which is driven in is one of the small wedges, if it is hit by many blows and is driven in, then it is driven in as far as the whole wedge is driven in by one whole blow, and this is by a movement corresponding to the blows, I mean by the measure of the blows $\mathrm{BH}, \mathrm{HH}, \mathrm{HT}$, ȚČ, and in the same way the ratio of time to time is like the ratio of blow to blow and that of the whole wedge head to the head of one of the small wedges. The smaller now the angle of the wedge becomes, the further will the wedge penetrate by a smaller force than the force that drives in the whole wedge. ${ }^{37}$

Although Heron states that 'the ratio of time to time is like the ratio of blow to blow', the meaning must be that the ratio of the times taken by two wedges to displace a load by a certain distance is the inverse of the ratio of the forces: a smaller force must act over a longer time to produce the same effect. If we halve the force of the blow and use a wedge which is twice as acute, we will need two blows instead of one, and these blows will take twice as long to split the load by the same amount. Moreover, this more acute wedge will have to penetrate twice as far into the load in order to split it by the same amount; thus the smaller force acts over a longer distance as well as a longer time. ${ }^{38}$

Although Heron does not set out equilibrium conditions for the wedge, this inverse proportionality between forces and times does supply an analogy to the equilibrium between force and weight in the concentric circles. In the wedge, a small force acting for a longer time (i.e. over a longer lateral distance) produces the same effect as a large force acting for a shorter time (distance). Thus just as in the concentric circles, the effect of a small force can equal that of a large one; the difference is that in the circles the effectiveness of a force depends on its distance from the center, while in the wedge it depends on the distance over which the force acts. Similarly, in the case of the screw Heron notes that a screw with tighter threads will be able to move a larger load by means of the same force, but it will require a greater time to do so. ${ }^{39}$ The key idea in the analyses of both the wedge and the screw is thus that of compensation between forces and the times (and distances) over which they act: if we reduce the force, we must increase the time (see further below, pp. XREF, on the phenomenon of 'slowing up').

After completing the reduction of all the powers to the circle, Heron makes what might seem a surprising remark:

\footnotetext{
${ }^{36}$ Another way of putting the point is as follows. Since the displacement of the load caused by the whole wedge MD when struck by the whole blow BČ is the sum of the displacements caused by the sub-wedges when struck by the sub-blows, each sub-wedge, driven in by a sub-blow, must displace the load (along the vertical axis) by an amount that stands in the same relation to the total displacement as the sub-blow stands to the whole blow. In order for this to happen, each sub-blow must drive in the sub-wedge over the same lateral distance (AD) as is covered by the whole wedge when struck by the whole blow.

${ }^{37}$ Mech. 2.17. Translation Drachmann (1963b, 73), modified.

${ }^{38}$ Alternatively, in figure 8, if the force BČ is applied to the whole wedge MD, the load will be displaced by MD in a given time t. But if the force $B H$, equal to $1 / 4 \mathrm{BCC}$, is applied to the sub-wedge $R D$, then the load will be moved by $1 / 4 \mathrm{MD}$ in time $t$ and by MD in $4 \mathrm{t}$.

${ }^{39}$ Mech. 2.17: 'And just as it has been explained about the wedge that the one that has a smaller angle moves the weight by less force than the force that moves the weight by a wedge with a greater angle, so we have to say about this that the screw in which the distances between the screw lines are less will move the weight with greater ease than the screw whose distances between the screw lines are greater will move it, because the lesser distance gives a smaller angle'. Translation Drachmann (1963b, 81), slightly modified.
} 
That the five powers that move the weight are like the circles around a single center, this is clear from the figures that we have drawn in the preceding chapters. But I think that their shape is nearer to that of the balance than to the shape of the circle, because in the beginning the first explanation of the circles came from the balance. For here it was shown that the ratio of the weight hung from the smaller arm to that hung from the greater arm is like the ratio of the larger part of the balance to the smaller. ${ }^{40}$

As we have seen, the analogy with the circle is clear in the cases of the wheel and axle and the lever; the discussion of the compound pulley, too, begins with an explicit reference to the concentric circles (2.11). It is hardly the case that Heron adopts the concentric circles as a starting point only as a nod to tradition. ${ }^{41}$ But in fact it is the balance that in one way or another underlies the entire analysis. The balance model is implicit in Heron's attempt to set out equilibrium conditions for the wheel and axle, the lever, and the pulley, and it plays a crucial role in the analysis of the lever in its second use (2.9; see below, p. XREF). In generalizing the analysis of the simple pulley to the compound case (2.12) Heron leaves behind any direct resemblance to the concentric circles. In the case of the wedge and the screw there is no obvious resemblance to the concentric circles at all; the analogy is limited to the point that a small force can overcome a large weight, by making the angle of the wedge smaller or the screw threads tighter. But of course the ability of a small force to overcome a large weight is precisely the feature of the concentric circles that Heron himself explains by reference to the balance.

In making the balance rather than the circle fundamental to his explanation of machines, Heron reverses the explanatory relationship between the circle and the balance from the Mechanical Problems; there, as noted above (p. XREF), it is the circle that explains the balance. Yet from another point of view the similarities between the two texts are larger than their differences. In the Mechanical Problems, as in Heron, the balance is fundamental to the explanation of all other machines. The balance explains the lever, and the lever in turn explains the working of most of the other machines discussed in the 35 problems. For both Heron and the author of the Mechanical Problems, the balance is a paradigmatic technological instrument that provides a concrete model for analyzing the relationship between force and weight, and in particular for understanding how a small force can balance or even overpower a large weight. The differences between Heron and the Aristotelian text are due, first, to Heron's recognition of the five powers as a distinct group of simple machines, and secondly to the impact on theoretical mechanics of Archimedes' proof of the law of the lever in On the Equilibrium of Planes. Neither of these points concerns the central importance of the balance as a starting point for theoretical reflection. ${ }^{42}$

\section{The powers in combination and the phenomenon of slowing up}

\footnotetext{
${ }^{40}$ Translation Drachmann (1963b, 81), slightly modified.

${ }^{41}$ Pace de Gandt (1982, 114).

${ }^{42}$ It must be kept in mind that Archimedes' own proof of the law of the lever in On the Equilibrium of Planes begins from a set of preliminary assumptions that in part describe the behavior of weights on the balance; see Renn, Damerow, and McLaughlin (2003). In any case the differences between the Aristotelian text and Heron are not helpfully characterized in terms of a distinction between a 'dynamical' and a 'statical' approach (Krafft 1970). True, Heron does not appeal to considerations of force and movement in discussing the concentric circles, as does the Mechanical Problems. But then Heron makes no attempt to prove the law of the lever at all; he simply accepts it as a given from Archimedes. As we have seen, Heron's analyses of the wedge and screw are based on 'dynamic' considerations of the relationship between forces, times, and distances, and he seems to hold that such relationships reflect a basic similarity to the balance.
} 
After completing the reduction of the five powers to the balance, Heron turns in 2.20 to the problem of how they can be combined to move a given (large) weight with a given (small) force. The problems involved are different for different powers. The lever and the wheel and axle have to be increased in size in order to achieve greater mechanical advantage; in the case of the compound pulley it is the number of pulleys that must be increased. The wedge and the screw, on the other hand, become more powerful with a decrease in size: the angle of the wedge must be made more acute, and the screw threads more tightly wound. Chapters 21-26 of book 2 discuss the combination of individual wheel and axles, levers, and compound pulleys, each of which is of manageable dimensions, to achieve a high mechanical advantage.
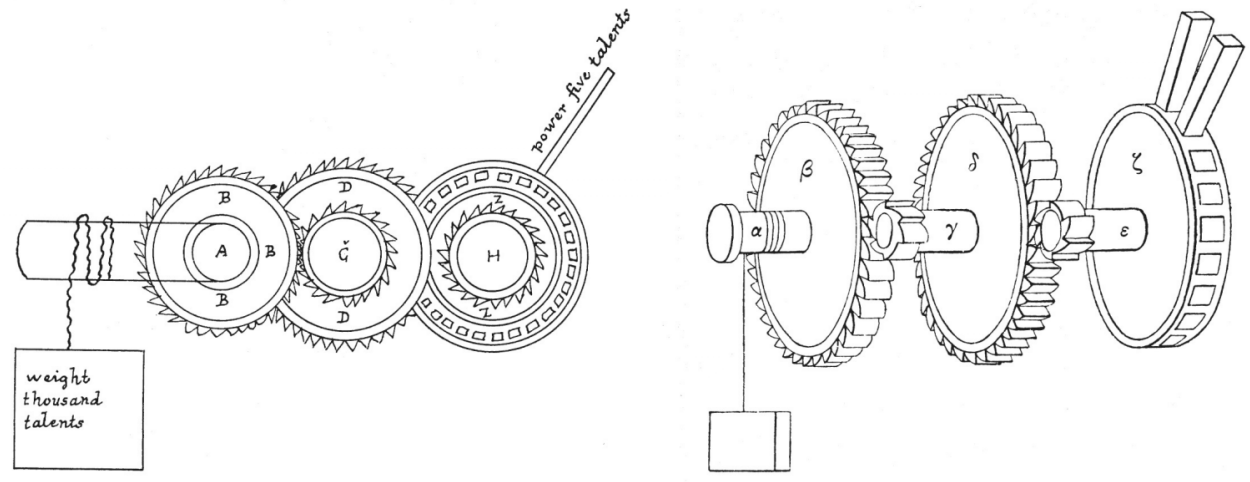

Figure 9: Combination of toothed wheels to move a force of 1000 talents with a force of 5 talents (Mech. 2.21). Drachmann's rendering of the figure in MS B is on the left (1963b, 84); the figure from Nix/Schmidt is on the right. Neither is exactly faithful to the text, which states that the wheel:axle ratios $B: A, D: \breve{C}$, and $Z: H$ are $5: 1,5: 1$, and $8: 1$, respectively.

As an example we may consider the use of a combination of wheel and axles to move a load of 1000 talents with a force of 5 talents (2.21; fig. 9). Given the results established in the reduction, this would require a wheel with a radius 200 times that of its axle. But Heron shows that the same mechanical advantage can be achieved by a combination of three wheel and axles with ratios of $5: 1,5: 1$, and $8: 1$, respectively. He first describes the construction of a device in which the force exactly balances the weight to be moved, then states that the same force can be made to set the weight in motion by increasing one of the wheel-axle ratios slightly. The same pattern is followed for the compound pulley and the lever: first a description of what is required to keep the given weight in equilibrium, then an indication of how to make the given force 'overpower' (Arabic qawiya) the weight. The procedure and the language reflect the continuing importance of the balance model in Heron's account. This becomes quite explicit in the Greek version of the description of the Baroulkos or 'weight-hauler' (fig. 10), a device very similar to the one described in 2.21:

These things having been done, if we imagine the chest $\alpha \beta \gamma \delta$ placed on high, and we tie the weight to the axle $\varepsilon \zeta$, and the pulling force to the wheel $\chi \psi$, neither side will go downwards, even if the axles are turning easily and the

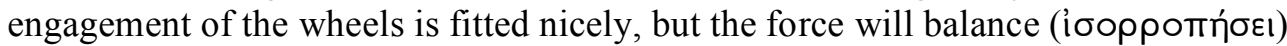

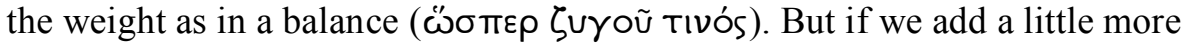
weight to one of them, the side where the weight is added will sink (К and go downwards, so that, if just the weight of one mina is added to the force 


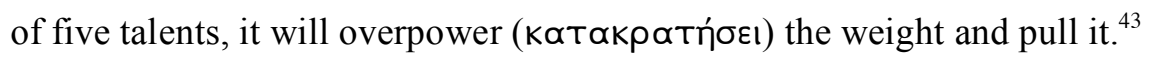
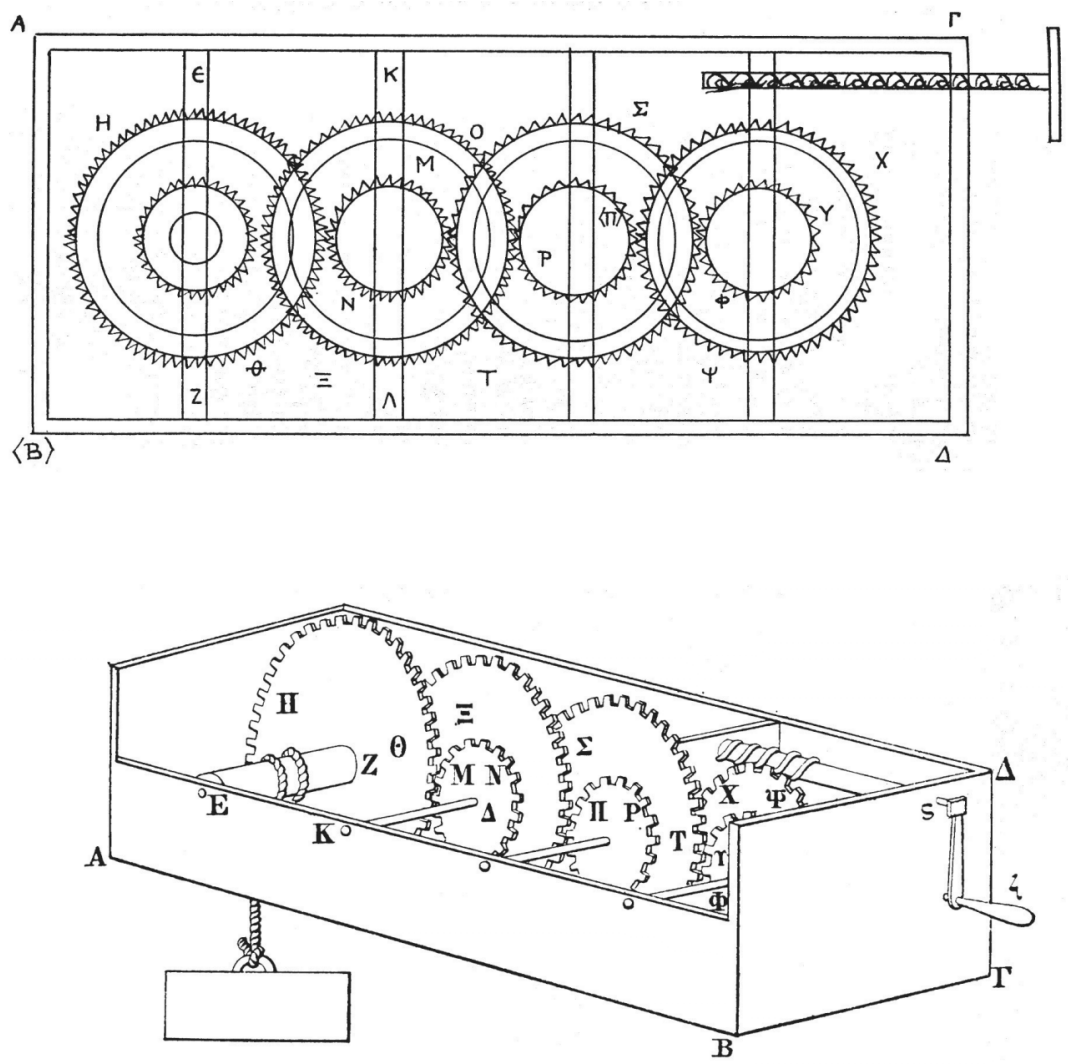

Figure 10: The Baroulkos (Heron Dioptra 37; Mech. 1.1; Pappus, pp. 1060-8 Hultsch). Above, Drachmann's drawing made from the Mynas Codex, a Greek manuscript of the Dioptra (1963b, 25); below, the drawing from the Teubner edition of H. Schöne.

As a final tour de force Heron describes how all the powers except for the wedge can be combined to achieve the same mechanical advantage of 200:1 (2.29; fig. 11).

\footnotetext{
${ }^{43}$ Heron Dioptra 37, 310.20-312.2 Schöne; translation Drachmann (1963b, 26). Throughout the passage

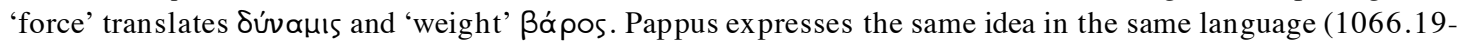
31 Hultsch); cf. also Heron Mech. 1.1. On the relationship between these descriptions see Drachmann (1963b, 22-32).
} 


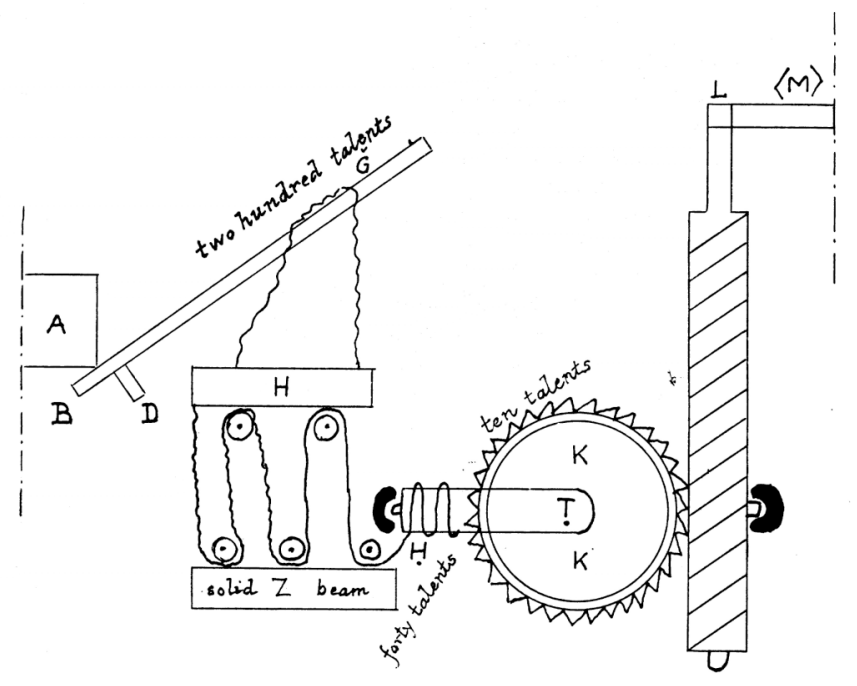

Figure 11: Combination of four powers to move a weight of 1000 talents with a force of 5 talents (Mech. 2.29). Drawing of a figure in MS L (Drachmann 1963b, 90).

The discussion of the powers in combination prompts Heron to remark on a further important aspect of their operation, the phenomenon of delay or 'slowing up'. The fullest description of this phenomenon comes in 2.22, in reference to the combination of wheel and axles described in 2.21:

In these tools and those like them with great force (quwwa) there will come a delay, because in proportion of the weakness of the moving force (al-quwwat al-muharrikat) to the great size of the weight moved (al-tiql al-mutaharrik), in this proportion we need time, and the ratio of force (quwwa) to force (quwwa) and time to time is the same. ${ }^{44}$

The same relationship between forces and times is asserted in similar language for the compound pulley (ch. 24), the lever (ch. 26), the wedge, and the screw (both in ch. 28). Although Heron's formulation is not as clear as it might be, it is evident from the passage quoted above that he is asserting an inverse proportionality between forces and times: the smaller the force, the more time is needed ('in proportion of the weakness of the moving force...in this proportion we need time'). The underlying idea is a comparison between the amount of time it takes for two machines of different mechanical advantage to perform a given task. Thus, letting $F_{1}$ and $F_{2}$ be the forces applied to machines 1 and 2, and $T_{1}$ and $T_{2}$ the times they require for performing a given task (e.g. lifting a weight a given distance), the following relation holds:

$$
\text { (R) } F_{1}: F_{2}:: T_{2}: T_{1}
$$
ch. 28:

This interpretation is clearly supported by Heron's remarks about the wedge and screw in

But that the delay is also found to take place in those two, that is evident, since many blows take more time than a single blow, and the turning of the screw many times takes more time than a single turn. And we have proven that the ratio of the angle to the angle of the wedge is like the ratio of the moving blow

\footnotetext{
44 Translation Drachmann (1963b, 85), modified.
} 
to the moving blow; and so the ratio of the time to the time will be like the ratio of the force (quwwa) to the force (quwwa). ${ }^{45}$

Heron refers back to his proof in 2.15 that a more acute wedge will produce the same effect as one that is less acute by means of less powerful blows. But it will take more time to do so, since the many blows take more time than a single strong blow; as the force decreases the time increases, in exact (but inverse) ratio. In order to split a load by the same amount as an obtuse wedge, the tip of an acute wedge must travel over proportionally more distance, which takes a correspondingly longer time (cf. above, p. XREF). It is important to note that this analysis presupposes that each blow takes the same amount of time to move the wedge a certain distance (i.e. the tip of the wedge moves at the same speed whether the blows are weak or strong: 'many blows take more time than a single blow'). A similar point follows for the screw, since it is just a twisted wedge; again, it is a crucial assumption that the number of turns of the screw in a given time remains the same (in the text above: "the turning of the screw many times takes more time than a single turn'). In the case of both wedge and screw, then, it is clear that Heron's understanding of the phenomenon of slowing up involves a comparison between machines of different mechanical advantage; moreover, this comparison assumes that the moving forces in the two machines travel at the same speed.

${ }^{45}$ Heron, Mech. 28. Translation Drachmann (1963b, 89), modified. 

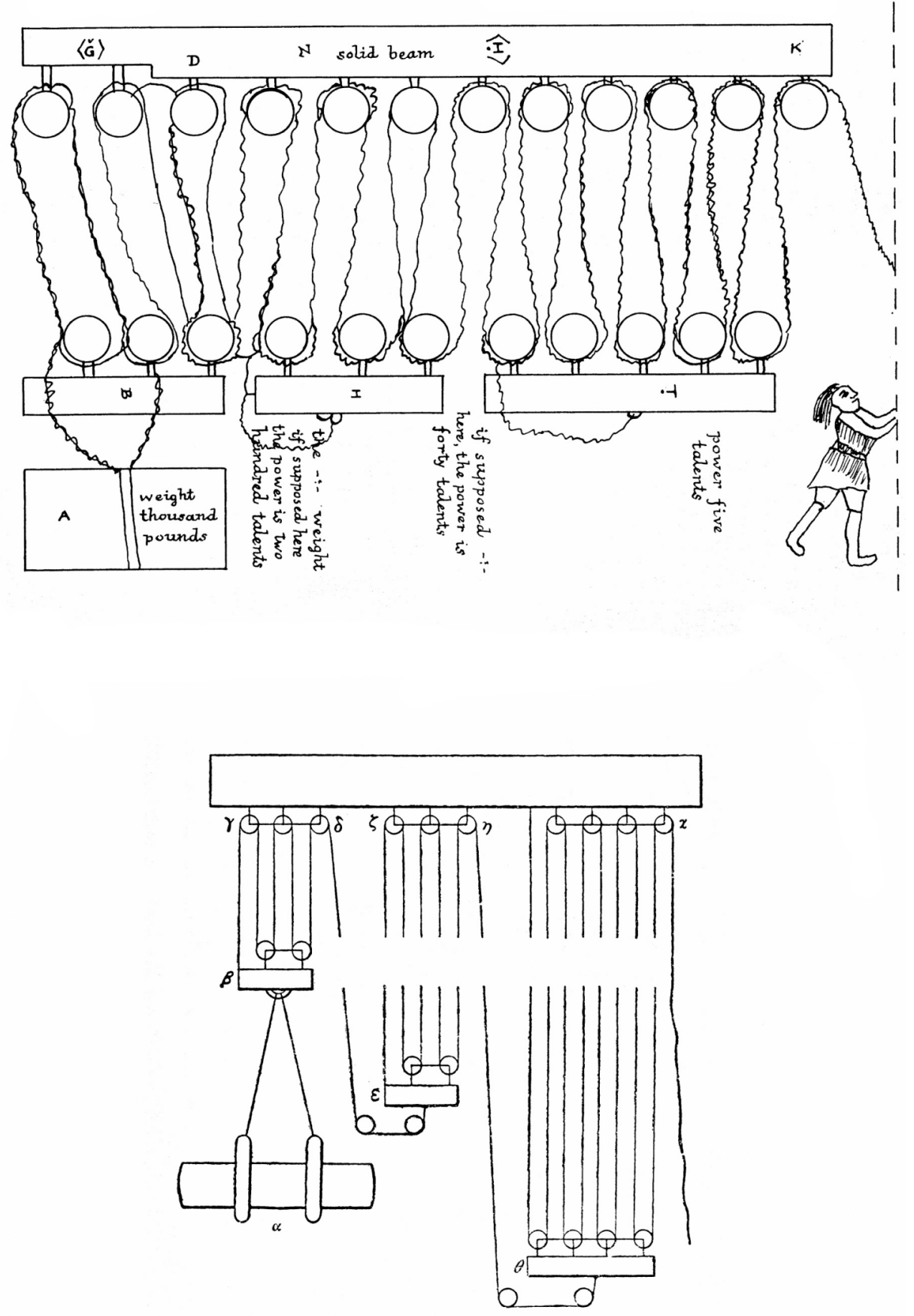

Figure 12: Combination of compound pulleys to move a weight of 1000 talents with a force of 5 talents. Drachmann's drawing above is from MS B (1963b, 87); the figure below is from Nix/Schmidt.

Such a comparison between moving forces also underlies Heron's account of slowing up in the case of the compound pulley (Mech.2.24, fig. 12; since the MS figure is not very clear, the following refers to the figure in Nix/Schmidt). Specifically, Heron notes that in order to lift a weight of 1000 talents at $\beta$ over the distance $\beta \gamma$, a force of 200 talents exerted at $\delta$ must be pulled through 5 times the distance $\beta \gamma$ (since each rope in the 5-pulley system $\beta \gamma$ must be pulled over a distance $\beta \gamma$ ). Similarly, a force of 40 talents exerted at $\eta$ must be pulled through 5 times the distance of the force at $\delta$ (since in order to move the rope at $\delta$ by a certain 
distance, the rope at $\eta$ must be pulled through 5 times that distance). Having noted this, Heron again remarks that 'the ratio of time to time is like the ratio of the moving force (alquwwat al-muharrikat) to the moving force(al-quwwat al-muharrikat) '. ${ }^{46}$ Thus, the analysis again presupposes a comparison between two moving forces traveling at the same speed. In order to lift the weight a given distance, the moving power at $\eta$ will have to travel farther than the moving power at $\delta$, and so will take a longer time. This indeed would immediately be evident in practice, since the length of rope that would have to be pulled through the machine to raise a weight a given distance would be much greater in a machine with more pulleys (as would the amount of time needed for the operation). Viewed in this way, Heron's explanation of the phenomenon of slowing up may be expressed as an inverse proportionality between the moving forces and the distances they must traverse in order to move the weight a given distance, i.e.

$$
\text { (R') } F_{1}: F_{2}:: D_{2}: D_{1}
$$

where $D_{1}$ and $D_{2}$ are the distances covered by the moving forces, traveling at a constant speed, in different times. ${ }^{47}$

Now the operation of the compound pulley can also be analyzed in a way that leads to a different understanding of the phenomenon of slowing up. On this view, the comparison is between the moving force and the weight moved, rather than between two different moving forces. If the moving force is smaller than the weight, it will cover more distance than the weight in any given time (e.g. in fig. 12 above, during the time in which the force at $\delta$ moves a certain distance, the weight at $\beta$ will move $1 / 5$ of that distance). Thus the moving force travels more quickly than the weight; in this sense, the 'slowing up' that occurs in the machine is the result of the weight moving more slowly than the force that moves it. At any given time the ratio of the distance covered by the moving force to that covered by the weight will be the inverse of the ratio of the force to the weight, i.e.

$$
\text { (R") } F_{1}: F_{2}:: D_{2}: D_{1}
$$

where $F_{2}$ equals the weight. Put another way, R" asserts that the product of force and distance traversed is the same for the weight and the moving force; it thus expresses the general principle that the work (understood as the product of force times distance) is the same on both the 'input' and 'output' sides of the machine: the work in equals the work out.

Some commentators have taken $\mathrm{R}$ " to be the basic principle underlying Heron's analysis of the phenomenon of slowing up. Thus Clagett writes $(1979,17)$ : 'A careful study of the examples shows that what is really involved is distance, i.e., that the ratio of force to force is inversely as the distances through which the forces act.' He goes on to argue $(1979,18)$ that $\mathrm{R}$ " amounts to a recognition of the concept of 'virtual work', according to which the equlibrium between the moving force and the weight is explained as due to the equivalence of the work that would be done on both sides of the machine if the force were to lift the weight by a certain amount (i.e. the product of force times distance traversed is the same for the weight and the moving force) ${ }^{48}$ But care is needed here. Although Heron was presumably well aware from practical experience that the moving force travels faster than the weight moved in a machine of high mechanical advantage, he nowhere states R" explicitly; instead,

\footnotetext{
${ }^{46}$ Heron, Mech. 24. Translation Drachmann (1963b, 89), modified.

${ }^{47}$ We may also compare the distances over which the weight is moved by the two moving forces in the same time. In this case, however, we have a direct proportionality between the forces and the distances over which the weight is moved, i.e. a smaller force moves the weight over a smaller distance in the same time as a larger force moves it over a greater distance, and the ratio of the forces is equal to the ratio of the distances.

${ }^{48}$ Clagett (1979, 18); cf. Vailati (1897).
} 
his explanations of the phenomenon of slowing up consistently refer to a comparison between different moving forces. ${ }^{49}$ In this respect, Heron's account is closely tied to the use of machines in practical situations, where a key issue is the amount of time taken by different machines to complete a given task ${ }^{50}$ Any practitioner with experience using compound pulleys or other such machines for lifting weights must have known that it would save time to increase the moving force (i.e. add another slave or an ox) rather than to employ a machine with greater mechanical advantage. The practical context also explains the assumption that the moving forces in the different machines travel at the same speed. The picture to keep in mind is of a workman pulling on the end of a rope that runs through a compound pulley system: even though he always walks at the same speed, it will take him less time to raise a given weight over a given distance if he uses a machine with fewer pulleys. ${ }^{51}$ It is therefore wrong to suppose that $\mathrm{R}$ " is the fundamental principle underlying Heron's explanation of the phenomenon of slowing up, or that he views it as the explanation of the equilibrium between a small force and a large weight. Rather, $\mathrm{R}^{\prime \prime}$ is a kind of spinoff result, one which is implicit in Heron's analysis but plays no important role in his reasoning. ${ }^{52}$

As we have seen, Heron's analysis of the five powers both takes its start from practitioners' knowledge and attempts to explain that knowledge. Nevertheless, Heron concludes his account with an acknowledgment that the relationships between force and weight that he has set out may not hold in practice:

Since we have now explained for each of these powers that it is possible by a known force

${ }^{49}$ The only prima facie exception is the passage from 2.22 quoted above (p. XREF), which seems to assert that the ratio of the times is the inverse of the ratio between the force and the weight moved. Yet a reference to time would be puzzling if Heron had meant to state or imply $\mathrm{R}^{\prime \prime}$, since that relationship presupposes that the times of motion are equal for the moving force and the weight ( $\mathrm{cf}$. next $\mathrm{n}$.). And in fact the discussion of the combination of wheel and axles that follows is precisely similar to the discussion of the compound pulley in ch. 24: the comparison is between the times taken by different moving forces applied at the circumference of different wheels to move the weight a given distance (alternatively, it is between the distances they travel in the different times they take to move the weight, assuming they move at the same speed). For example, in fig. 9 above, a force of 40 talents applied at the circumference of wheel D must cover 5 times the distance as a force of 200 talents applied at the circumference of wheel B in order to raise the weight by the same distance (the wheel D must turn five times for the wheel B to turn once, and the two wheels have the same circumference). Heron concludes by stating the usual relationship between moving forces: 'the ratio of the moving force (al-quwwat al-muharrikat) to the moving force (al-quwwat al-muharrikat) is inverse <of the ratio of time to time>' (Drachmann $(1963 \mathrm{~b}, 86)$ translates 'the proportion between the moving power and the power moved is inverse', but there is no basis in Nix's Arabic text for the variation and Drachmann does not indicate any alternative manuscript readings; nevertheless, a supplement such as the one he proposes ('of the ratio of time to time') seems necessary). As for the lever (ch. 26), Heron simply appeals to the analogy between the lever and the wheel and axle: 'and just as we have proved for these axles that the ratio of the force to the force is like the ratio of the time to the time, so we prove it also here' (translation Drachmann 1963b, 89, modified).

\footnotetext{
${ }^{50}$ To be sure, one can compare the amount of time taken by a given moving power to move a given weight over a given distance to the amount of time it would take for a force equal to the weight itself to do so. That is, we can set $F_{2}$ equal to the weight in $\mathrm{R}^{\prime}$ above and thereby obtain an inverse proportionality between forces and distances $\left(F_{1}\right.$ $\left.\therefore F_{2}: \because D_{2}: D_{1}\right)$. But here the distances $D_{1}$ and $D_{2}$ are those covered by the forces in different times: given two moving forces traveling at the same speed, one of which is equal to the weight, the force equal to the weight will lift it much more quickly than a force much smaller than the weight. Though this is superficially similar to R" it is in fact quite different, and does not imply a recognition of a general principle (work in equals work out) such as is implicit in R".

${ }^{51}$ Strictly speaking, it is not necessary that the worker walks at a constant speed, only that the speeds vary in the same proportions in the two machines. (I owe this point to Sophie Roux.)

${ }^{52}$ Cf. de Gandt (1982, 114-5; 127).
} 
to move a known weight, it is necessary also to explain that if it were possible that all the parts made were turned accurately, of equal weight, with parts of the same smoothness, then it would be possible with each of these engines to perform the work we have described in the given proportion. But since it is not possible for human beings to make them perfect in smoothness and uniformity, it is necessary to increase the force on account of what may occur of roughness in the engines, and we must make them greater, and so we increase their size above the proportion we have first given, so that no hindrance occurs herein, and what we find by the use of the engines shall not make out wrong what was correct in our theoretical proof. ${ }^{53}$

Heron acknowledges that he has been discussing machines in their ideal form; to this extent his account is a theoretical one. Yet it should be noted, first, that the contrast expressed here is a contrast between ideal and actual physical machines, rather than between a mathematical idealization and its physical realization. And however wide the discrepancy between theoretical analysis and actual practice, Heron's purpose is to explain that discrepancy so that a practitioner will not be led to doubt the correctness of the theoretical analysis.

\section{Mechanics, physics, and the search for principles}

The behavior of the five mechanical powers, in particular their ability to move a large weight with a small force, challenged the basic physical assumption that a weight can be lifted only by a force equal to it. The five powers brought about effects that at first seemed wondrous or paradoxical, and which therefore might be thought to lie outside the scope of physics understood as the knowledge of natural regularities. But Heron's account shows how the balance could be used as a model to provide a theoretical explanation of the behavior of the five powers. Once the causes of mechanical phenomena were understood, they became a part of physics rather than a challenge to it. This at any rate is suggested by the opening of Mech. 2.33:

It is now absolutely necessary for those who occupy themselves with the science of mechanics to know the causes that are in effect in the use of each motion, as we have explained for the lifting of heavy objects with natural [i.e. physical] proofs (bi-al-barāhin $a l-t a b i$ ' $i y y a t$ ), and set out everything that occurs with each individual of the powers mentioned... Now we want to talk of things that the ancients already stated, because of the usefulness they have in this chapter, and we are going to wonder at the things that, when we have proven them, will be the contrary to what we had knowledge of before. The beginning (ibtidā', presumably ä $\rho \times \eta$ ) for the things that we are going to research, we derive from what is clear to us. The things of whose causes we can only talk after the most clear objects will, however, even increase our amazement when we see that the things that we apply are contrary to what we have gotten used to and what was certain for us. It is now clear that anyone who wants to find the causes thoroughly, necessarily has to apply natural [i.e. physical] principles (ibtidā' àt tabi 'iyyat), either one or more, and has to link everything that he researches with them, and that the solution of every single question is given fundamentally if its cause has been found and this is something that we have already understood. ${ }^{54}$

The mention of 'wonder' and 'amazement' recalls the opening of the Mechanical Problems, a text that emphasizes the wondrous ( $\theta$ aupaorós) character of mechanical phenomena as taking place in a way that is 'beyond nature' ( $\pi \alpha \rho \dot{\alpha}$ qúoıv). But the references to 'natural proofs', 'natural principles', and the idea that the search for such principles begins from

\footnotetext{
${ }^{53}$ Mech. 32. Translation Drachmann (1963b, 93), slightly modified.

${ }^{54}$ Translation based on the German of Nix.
} 
something that is 'clear to us' are unmistakable allusions to the opening of Aristotle's Physics (e.g. 184a1 - b14). Heron is in fact arguing that mechanical phenomena, despite the fact that they initially seem to violate natural regularities, can be integrated into the study of nature (i.e. physics). Since this passage comes immediately after Heron's account of the five powers and makes direct reference to it, it seems that Heron views his explanations of the five powers as based on such 'natural principles'. ${ }^{55}$

Yet the application of the balance model also led Heron to conclusions that were in tension with both practitioners' knowledge and deeply-held assumptions of much ancient physical thought. One of these assumptions is the idea that a body in motion requires a force to keep it moving, a notion that may be dubbed 'motion implies force'. That some effort must be exerted to keep a body in motion is manifestly the case in many practical situations because of friction. In Aristotle's natural philosophy, all forced motion requires a mover to sustain it; though this view corresponds to many everyday experiences, it leads to notorious difficulties in the case of phenomena such as projectile motion (e.g. Ar. Phys. 266 b $25 \mathrm{ff}$.). The enduring plausibility of the idea that motion implies force is reflected in the fact that it corresponds to the intuitive understanding of many physics students even today. ${ }^{56}$ Its rejection marked an important step towards the development of the concept of inertia in classical mechanics.

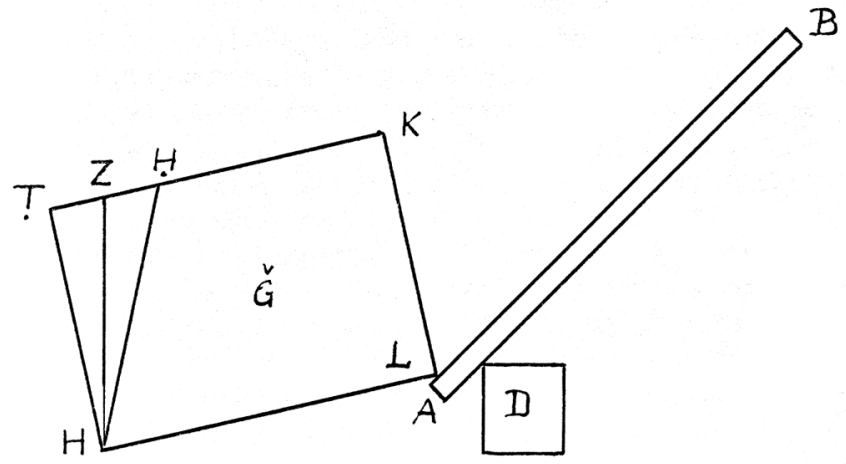

Figure 13: The lever, second use (Mech. 2.9). Drachmann's reconstruction (1963b, 65), made from the figure in MS L.

As a first example of the way in which the application of the balance model challenged the idea that motion implies force we may consider Heron's discussion of the lever in its second use, viz. where the load rests partly on the ground and turns around a fixed point as it is lifted (2.9, fig. 13). As in the simple case analyzed in 2.8 , the moving force applied at the end of the lever corresponds to the force on the larger circle and the load to the weight on the smaller circle. But because the load rests partly on the ground, it requires less force to move it than in the other case. We imagine a vertical line $\mathrm{HZ}$ drawn through the corner of the load that remains on the ground. The portion of the load to the left of this line (HTZ) is in equilibrium with the portion $\mathrm{HZH}$ to the right of it; then if one imagines the entire portion HṬ separated from the load, it will not incline to either side, and it will not take any force (quwwa) at all to move it. Thus the lever needs to balance only portion HHKL of the load, which diminishes as the load is turned around the point $\mathrm{H}$. Eventually the load will reach a position where the line $\mathrm{HZ}$ divides it exactly in two; at that

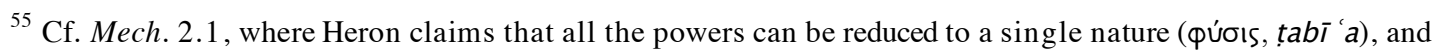
Mech. 1.34: 'In the following we are going to deal with the five powers by means of which weights are moved, explain what they are based on and how the natural effect $(a /-f i$ 'I al-țabi ' $I$ ) in them occurs'.

${ }^{56}$ See Clement (1983). 
point it will take no force (quwwa) at all to move it: 'and it is placed in a position that does not need any force, if the imagined surface going through the sign $\mathrm{H}$ at right angles to the horizon divides the burden into two halves'. ${ }^{57}$ The key step in the argument is a mental operation of dividing the load into different parts which hold one another in equilibrium like two weights on a balance. ${ }^{58}$ Thus, the application of the balance model leads Heron to the conclusion that no force at all is required to move a body that is perfectly balanced on a point.

To a certain extent, of course, this analysis corresponds to a basic fact of practical experience, viz. that the amount of force required to move a body with a lever used in the way shown in fig. 13 decreases as the body is lifted. In chapters 20-24 of book 1, however, Heron goes substantially further than this and directly attacks the notion that a weight (tiql) can only be moved by a force (quwwa) equal to it:

There are those who think that weights lying on the ground can be moved only by a force equal to them, wherein they hold wrong opinions. So let us prove that weights lying in the way described are moved by a force smaller than any known force, and we shall explain the reason why this is not evident in practice. $^{59}$

As often in Heron, the argument is put in the form of a thought experiment. We are to imagine a smooth, solid body lying on a plane surface. If this surface is tilted to the left, however slightly, the body will slide downwards because of its natural inclination; similarly, it will slide downwards to the right if the surface is tilted to the right. The situation in which the surface is horizontal thus represents a state of equilibrium in which the body is equally disposed to move to the left and to the right. The conclusion is that the body can be set in motion by a force that it as small as one likes:

And the weight that is ready to go to every side, how can it fail to require a very small force to move it, of the size of the force that will incline it? And so the weight is moved by any small force. ${ }^{60}$

The idea seems to be that the effect of a force on such a weight is simply to cause it to incline in one direction; it will then continue to move on its own as if it were on an inclined surface. It takes a force to set a body in motion, but not to keep it moving. Heron goes on to suggest that the behavior of water is analogous because of its fluidity and mobility (1.21). Conversely, the coherence and resistance of solid bodies explains why they do not behave in the same way, and why rollers and other means were invented for transporting loads over the ground.

\footnotetext{
${ }^{57}$ Translation Drachmann $(1963 \mathrm{~b}, 65)$, modified. There are some textual problems in the chapter, but the basic character of Heron's analysis is not in doubt; see Drachmann (1963b, 65-7).

${ }^{58}$ It is perhaps because this analysis so clearly appeals to the balance that Heron ends the chapter with a remark that might otherwise seem out of place: 'And this effect of the lever can be referred to (mansüba) the circle, but it is not the same as the first effect. And that the balance also can be referred to (mansüba) the circle is evident, because the circle is a sort of balance' (tr. Drachmann $(1963 b, 46)$ ). In the final analysis, of course, Heron holds that it is the balance that explains the circle rather than vice versa $(2.20$; above, p. XXX).

${ }^{59}$ Mech. 1.20. Translation Drachmann (1963b, 46), modified.

${ }^{60}$ Mech. 1.20. Translation Drachmann (1963b, 46), modified.
} 


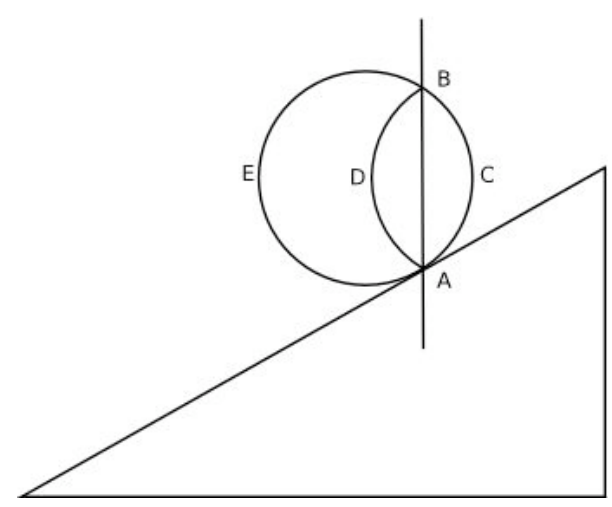

Figure 14: Heron's analysis of the inclined plane (modern reconstruction based on the text of Mech. 1.23; there is no figure in manuscripts B or L).

In 1.22 Heron turns to the topic of lifting weights, and makes the familiar claim that the force needed to lift a weight without the use of a machine is equal to that weight. ${ }^{61}$ If we imagine two equal weights suspended from the ends of a rope wound around a pulley, they will balance one another; if some weight is added to one side, it will overpower the weight on the other side and draw it upwards, 'unless there arises friction in the turning of the block or stiffness in the ropes'. ${ }^{62}$ This leads immediately to a discussion of the force needed to draw an object up an inclined plane (1.23; fig. 14). Heron approaches the problem by asking how much force is needed to balance a weight lying on an inclined plane. He considers the special case of a cylinder and imagines a vertical line $(A B)$ cutting the cylinder at the point at which it touches the plane. The weight of the portion of the cylinder to the right of this line (ABC) balances the weight of an equal portion to its left (ABD). Heron concludes that no force at all is needed to move these two portions of the cylinder up the inclined plane; the force necessary to keep the cylinder in equilibrium will be equal to the weight of the other portion of the cylinder (ADBEA), and a slight increase will lift the cylinder. Heron does not attempt a precise calculation of the weight of the portion of the cylinder that must be held in equilibrium by the force. But his analysis implies that as the plane approaches vertical the portion ADBCA shrinks to zero, so that a force equal to the weight of the cylinder is required to lift it in a vertical direction. As the plane becomes more level the portion ADBCA grows larger, and when the plane is completely level the portion ADBCA is equal to the entire cylinder. The implication (as in 1.20) is that no force at all is needed to keep the cylinder rolling along a level surface, once it has been set in motion.

In these chapters of book 1 the gap between theoretical results and practical experience is wider than anywhere else in Heron's Mechanics; the remarks on friction in 1.21 and 1.22 indicate that Heron was well aware of this fact. But he does not draw out the implications of his analysis of the inclined plane, much less generalize them and introduce a new theory of physics based on the rejection of 'motion implies force'. While Heron's application of the balance model leads to results that are at variance with basic assumptions of everyday experience as well as practitioners' knowledge, this tension did not lead to a transformation of the conceptual foundations of mechanical knowledge.

\footnotetext{
${ }^{61}$ Cf. above, n. 19.

62 Translation Drachmann (1963b, 47).
} 


\section{Conclusion: Transmission and Impact}

The first stage in the transmission of Heron's Mechanics is marked by the inclusion of extensive excerpts in the eighth book of Pappus of Alexandria's Mathematical Collection (pp. 1114-35 Hultsch). In introducing these excerpts, Pappus draws attention to the difficulty of consulting Heron's original text at the time when he was writing (the third century AD):

As for the aforementioned five powers, we shall set out a selection (žk $\theta \varepsilon \sigma 1 \zeta$ ) from the works of Heron as an aide-memoire (úmónvnols) for lovers of learning. In addition we wish to mention the essential things that have been said about the devices with one part, with two parts, with three parts, and with four parts [i.e. the lifting devices discussed in Mechanics 3.1-12], lest a person may seek in vain for the books in which these things have been written. For we have come across books that were corrupt in many parts, with their beginnings and ends missing. ${ }^{63}$

Notably, Pappus' excerpts are drawn from the sections of Heron's text that are closest to practitioners' knowledge: the account of the construction and use of the five powers in 2.1-6, and the descriptions of lifting devices in 3.1-12. ${ }^{64}$ Book 8 of Pappus' Collection seems to have circulated as an independent manual of mechanics in late antiquity; that it did so in the Arab world is proved by the existence of a self-standing Arabic translation. ${ }^{65}$ Although Heron's Mechanics also circulated in the Arab world in various versions, none of these seems to have reached the West until the seventeenth century. ${ }^{66}$

Against this background, the close parallels between Heron's Mechanics and a number of early modern texts are especially remarkable. I shall confine myself to three examples. (1) In his Mechanicorum Liber of 1581, Guidobaldo del Monte attempts to reduce each of the five mechanical powers or potentiae (the lever, pulley, wheel and axle, wedge, and screw) to the balance. (2) In a discussion of the inclined plane in his early De Motu Antiquiora (ca. 1590), Galileo asserts that a body lying on a smooth horizontal surface can be moved by 'the smallest of all possible forces'; his reasoning is closely similar to that employed by Heron in $1.20{ }^{67}$ (3) In his 1597 work De gli elementi mechanici, Niccolà Antonio Stelliola offers an analysis of the inclined plane that makes use of the balance model in a way very similar to Heron's procedure in 1.23 (fig. 15) ${ }^{68}$ What are we to make of such parallels?

\footnotetext{
${ }^{63}$ Pappus 8, 1114.22-1116.7 Hultsch.

${ }^{64}$ The Greek text of Pappus ends with the section corresponding to Mech. 3.2, but excerpts of 3.3-12 survive in the Arabic version edited by Jackson (1970).

${ }^{65}$ For an edition with translation of the Arabic version see Jackson (1970). Eutocius refers to Pappus 8 as the 'Introduction to Mechanics' ( $\mu \eta \chi \alpha \nu ı \alpha \alpha i ̀ ~ \varepsilon i \sigma a \gamma \omega \gamma \alpha i ́)$ at Comm. in libros Archimedis de sphaera et cylindro 70.6; cf. also the introduction to Jackson (1970).

${ }^{66}$ For an introduction to the Arabic transmission see Nix and Schimidt (1900, xv-xviii). The great Dutch Arabist Jacob Golius translated the Mechanics in the seventeenth century, but his work seems to have had no impact in scientific circles; see Carra de Vaux (1894, 8-9) and Brugmans (1784-85) (reprinted in Sezgin (2001)).

${ }^{67}$ Drabkin and Drake $(1960,66)$ : 'A body subject to no external resistance on a plane sloping no matter how little below the horizon will move down [the plane] in natural motion, without the application of any external force. This can be seen in the case of water. And the same body on a plane sloping upward, no matter how little, above the horizon, does not move up [the plane] except by force. And so the conclusion remains that on the horizontal plane itself the motion of the body is neither natural nor forced. But if its motion is not forced motion, then it can be made to move by the smallest of all possible forces'.
}

${ }^{68}$ Stelliola (1597, 41-2). Specifically, Stelliola's claim is expressed in terms of the concept of 'moment' (momento): 'il momento della rota appoggiata al piano, al momento della rota sospesa, la ha ragione, che l'eccesso delle portioni del circolo [sc. the area DHFGD], al circolo tutto'. The key step, as in Heron, is to 


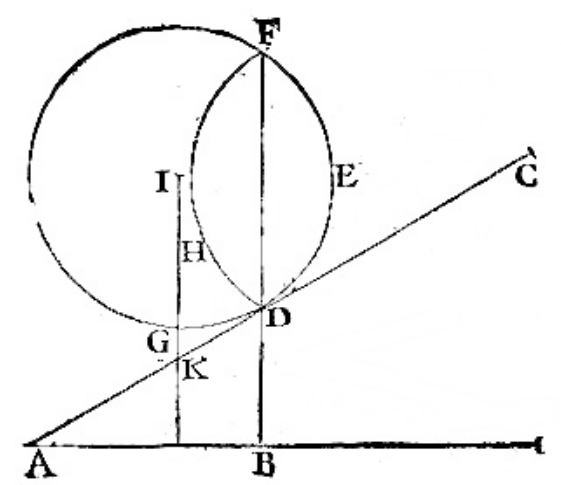

Figure 15: Stelliola's analysis of the inclined plane (De gli elementi mechanici 41).

It is certainly possible that Heron's Mechanics was better known in the early modern period than has generally been recognized; further research may bring to light new avenues by which the transmission of Heron's text facilitated the transmission of ideas ${ }^{69}$ But in fact the parallels we have noted take on even more significance if the Mechanics was completely unknown in the Renaissance. Like Heron, the Renaissance authors had both the Mechanical Problems and Archimedes at their disposal; they too attempted to analyze the operation of complex machines by reducing them to simpler ones such as the balance or lever. From this point of view, Heron's Mechanics provides an independent test case of what can be achieved by building on the conceptual foundations laid down by Archimedes and the author of the Mechanical Problems. That different authors working from the same conceptual foundations offer similar analyses of phenomena such as the inclined plane is not in itself surprising. But a recognition of this fact is an important step towards understanding the long-term stability of mechanical thinking and the reasons that led to its eventual transformation. ${ }^{78}$

\section{References}

Brugmans, A. (1784-85). Specimen mechanicae veterum per mechanicam recentiorem plenius expositum, Commentationes societatis regiae scientiarum Gottingensis, Mathematicae Classis 7: 75-88.

Carra de Vaux, B. (1894). Les Mécaniques ou L'élévateur de Héron de Alexandrie, publiées pour la première fois sur la version arabe de Qostâ ibn Lûqâ, et traduites en français, Paris: Imprimerie Nationale. Reprinted 1988 with an introduction by D. R. Hill and commentary by A. G. Drachmann, Paris: Les Belles Lettres.

Clagett, M. (1979). The science of mechanics in the Middle Ages, University of Wisconsin Press.

recognize that DFE balances DFH; thus it makes no contribution to the momento of the circle lying on the inclined plane.

${ }^{69}$ Cf. Russo (2004, 352-3).

${ }^{70}$ I would like to express my thanks to all those who discussed an earlier version of this paper with me at the Tenerife meeting, and especially to Roy Laird and Sophie Roux for their very helpful written comments. The paper was largely written during a sabbatical stay at the Max Planck Institute for the History of Science in Berlin, and I am deeply grateful to Jürgen Renn for his invitation to spend the academic year 2003-2004 there. 
Clement, J. (1983). A conceptual model discussed by Galileo and used intuitively by physics students, in D. Gentner and A. Stevens (eds), Mental models, Hillsdale, NJ: Erlbaum, pp. $325-40$.

Damerow, P. and Lefèvre, W. (1994). Wissenssysteme im geschichtlichen Wandel, number 5 in Preprints, Max Planck Institute for the History of Science, Berlin.

de Gandt, F. (1982). Force et science des machines, in J. Barnes, J. Brunschwig, M. Burnyeat and M. Schofield (eds), Science and speculation: studies in Hellenistic theory and practice, Cambridge University Press, Cambridge, pp. 96-127.

Drabkin, I. and Drake, S. (1960). Galileo: On Motion and On Mechanics, Madison: University of Wisconsin Press.

Drachmann, A. G. (1932). Ancient oil mills and presses, Vol. 1,1 of Kgl. Danske Videnskabernes Selskab, Archaeologisk-kunsthistoriske meddelelser, Levin \& Munksgaard, Kobenhavn.

Drachmann, A. G. (1936). Heron's screwcutter, Journal of Hellenic Studies 56: 72-77.

Drachmann, A. G. (1956). A note on ancient cranes, in C. Singer (ed.), A history of technology, Vol. II, Clarendon Press, Oxford, pp. 658-662.

Drachmann, A. G. (1963a). Fragments from Archimedes in Heron's mechanics, Centaurus 8: 91-146.

Drachmann, A. G. (1963b). The mechanical technology of Greek and Roman antiquity, Copenhagen: Munksgard.

Jackson, D. E. P. (1970). The Arabic version of the mathematical collection of Pappus Alexandrinus, book VIII, PhD thesis, University of Cambridge.

Krafft, F. (1970). Dynamische und statische Betrachtungsweise in der antiken Mechanik, Franz Steiner Verlag.

Nix, L. and Schimidt, W. (1900). Heronis Alexandrini opera quae supersunt omnia. Volumen ii: Mechanica et catoptrica, B.G. Teubner, Leipzig.

Renn, J., Damerow, P. and McLaughlin, P. (2003). Aristotle, Archimedes, Euclid, and the origin of mechanics: the perspective of historical epistemology, in J. L. M. Sirera (ed.), Symposium Arquímedes, Max Planck Institute for the History of Science, Preprint 239, pp. $43-59$.

Russo, L. (2004). The forgotten revolution: how science was born in 300 BC and why it had to be reborn, Berlin: Springer Verlag.

Sezgin, F. (ed.) (2001). Hero of Alexandria in the Arabic tradition: texts and studies, Frankfurt am Main: Institute for the History of Arabic-Islamic Science at the Johann Wolfgang Goethe Universität.

Stelliola, N. A. (1597). De gli elementi mechanici, Napoli: Porta Regale.

Vailati, G. (1897). Il principio dei lavori virtuali da Aristotele a Erone d'Alessandria, Atti della R. Accademia delle Scienze di Torino. 